Voix et Images

volxetimages

\title{
Problèmes de sémiologie théâtrale, de Patrice Pavis
}

\section{Bernard Andrès}

Volume 2, numéro 3, avril 1977

Jean Éthier-Blais

URI : https://id.erudit.org/iderudit/200076ar

DOI : https://doi.org/10.7202/200076ar

Aller au sommaire du numéro

\section{Éditeur(s)}

Les Presses de l'Université du Québec

\section{ISSN}

0318-9201 (imprimé)

1705-933X (numérique)

Découvrir la revue

\section{Citer cet article}

Andrès, B. (1977). Problèmes de sémiologie théâtrale, de Patrice Pavis. Voix et Images, 2(3), 439-440. https://doi.org/10.7202/200076ar d'utilisation que vous pouvez consulter en ligne.

https://apropos.erudit.org/fr/usagers/politique-dutilisation/ 


\section{Problèmes de sémiologie théâtrale, de Patrice Pavis}

Les Problèmes de sémiologie théâtrale de Patrice Pavis ${ }^{1}$ ont l'avantage de proposer, dans un langage rigoureux mais accessible, une analyse du phénomène théâtral fondée sur autre chose que le commentaire littéraire de texte et la subjectivité du critique. Pavis note bien que l'appareil critique traditionnel, en théâtre, nous vient des plus belles heures du réalisme et du naturalisme, au XIXe siècle. Après "l'exil du théâtre du royaume de la littérature, explique l'auteur, il faut trouver des outils capables d'examiner le théâtre comme système artistique et non comme.un succédané de la réalité". Non que Pavis élude le problème épineux de la référence: ce n'est qu'au terme de l'analyse qu'il posera l'hypothèse du rapport symbolique entre l'œuvre et le milieu. Il s'agit d'abord d'établir, à la suite de Mukarovsky, une théorie du théâtre qui le consacre dans sa spécificité signifiante. Pavis cite Artaud, à l'origine de sa démarche: “C'est autour de la mise en scène, considérée non comme simple degré de réfraction d'un texte sur la scène mais comme le point de départ de toute création théâtrale, que se constituera le langage type du théâtre $[. .$.$] ; il faut trouver$ des moyens nouveaux de noter ce langage, soit que ces moyens s'apparentent à ceux de la transcription musicale, soit qu'on fasse usage d'une manière de langage chiffré."

La perspective sémiologique met précisément l'accent sur le signifiant et la production du sens dans tout système linguistique. Au théâtre elle s'emploie, depuis les dix dernières années, à définir la spécificité du langage scénique, dans le prolongement des intuitions d'A. Artaud et des travaux d'A. Veinstein, de $V$. Meyerhold et de $B$. Dort, notamment. Même si le champ d'application reste surtout limité pour les fins de la démonstration, à la Mort de Danton, de Georg Büchner et à Marat-Sade, de Peter Weiss, on trouve chez Pavis une synthèse indispensable des travaux récents publiés dans Poétique, Langage, Littérature et surtout Semiotica. Sur ces bases, Pavis élabore un métalangage théâtral articulé sur les notions d'icône et de symbole (rendant compte de la valeur sémantique des signes théâtraux) et, toujours dans la terminologie de Peirce, du concept d'index définissant entre les signes une suite de relations dynamiques (narrativité). Il est évident que ni le décor, ni l'éclairage ou l'accessoire, la gestualité, la mimique, le costume ou le son (texte, musique ou bruit), aucun de ces signes n'est purement iconique, indiciel ou symbolique: tout se joue sur la prédominance de l'un ou l'autre de ces facteurs dans chaque signe. L'intérêt repose précisément sur l'agencement de ces registres dans la composition du code ou du message: "la sémiologie du théâtre devra donc, à partir du texte dramatique, reconstituer un code théâtral, code qui autoriserait (s'il existe vraiment) un retour au texte et un déchiffrage com- 